\title{
A EDUCAÇÃO SOCIAL NOS NOVOS ESPAÇOS E TEMPOS: AS REALIDADES ENTRONCADAS DA INTERVENÇÃO SOCIAL E EDUCATIVA
}

\author{
LA EDUCACIÓN SOCIAL EN LOS NUEVOS ESPACIOS Y TIEMPOS: LAS \\ REALIDADES DE ENCUENTRO DE LA INTERVENCIÓN SOCIAL Y EDUCATIVA
}

\author{
SOCIAL EDUCATION IN THE NEW SPACES AND TIMES: THE \\ INTERTWINED REALITIES OF SOCIAL AND EDUCATIONAL INTERVENTION
}

Ernesto Candeias MARTINS ${ }^{1}$

RESUMO: O artigo norteia-se pelos seguintes objetivos, na base de uma metodologia hermenêutica (analítica) que coincide com os pontos estruturais do texto: Analisar os indícios/vestígios da realidade atual e o reto da educação social; Clarificar conceptual e semanticamente a pedagogia social e educação social, no âmbito das Ciências da Educação; Compreender a (inter)relação entre a pedagogia social (âmbito teórico) e a educação social (âmbito prático), especialmente a prática da ação pedagógico-social do educador social na comunidade; Aprofundar a pedagogia social e educação social no contexto da intervenção social escolar. Servimo-nos de um quadro teórico-conceptual norteado por um conjunto de estudos de especialistas sobre a pedagogia social e educação social, que nos levaram a aprofundar estes conceitos nos novos espaços e tempos atuais da sociedade em geral. Os espaços e tempos na atualidade marcam a Pedagogia no âmbito social, seja ao nível escolar e não-escolar. Sabemos que a globalização fez proliferar 'espaço e tempo' no aprender e nas formas de conviver, com novas caraterísticas e áreas de ação ou intervenção. Pretendemos que a educação social inclua uma série de caraterísticas de intervenção, relacionadas com áreas específicas que são hoje fundamentais, para além daquelas que a sua evolução e identidade têm abarcado, por exemplo: educação escolar de adultos, gerontológica e intergeracional; o empreendedorismo social; a educação ambiental e ecológica; a gestão e promoção da cultura, do patrimônio e do turismo ecológico/rural; os imigrantes, os refugiados e os grupos étnicos; a promoção da mulher; a mediação (escolar, social), etc.

PALAVRAS-CHAVE: Educação social. Intervenção social e escolar. Pedagogia social. Novas realidades sociais. Profissão.

RESUMEN: El artículo se guía por los siguientes objetivos, basados en una metodología hermenéutica (analítica) que coincide con los puntos estructurales del texto: Analizar las evidencias / huellas de la realidad actual y la educación social directa; Clarificar conceptual y semánticamente la pedagogía social y la educación social, en el ámbito de las Ciencias de la Educación; Comprender la (inter) relación entre pedagogía social (alcance teórico) y

\footnotetext{
${ }^{1}$ Instituto Politécnico de Castelo Branco (IPCB), Castelo Branco - Portugal. Coordenador do Mestrado de Intervenção Social Escolar e membro de comissões científicas de mestrados na Escola Superior de Educação. Doutor em Educação/Ciências da Educação. Coordenou como responsável institucional o Projeto Transfronteiriço entre Universidad de Extremadura (Badajoz-Espanha) 'Programa de Inteligência Emocional em alunos da Educação Básica na Região de Castelo Branco' (entre 2011-2017). ORCID: https://orcid.org/0000-0003-48411215. E-mail: ernesto@ipcb.pt
}

RIAEE - Revista Ibero-Americana de Estudos em Educação, Araraquara, v. 15, n. esp. 3, p. 2167-2187, nov., 2020. e-ISSN: 1982-5587 
educación social (alcance práctico), especialmente la práctica de la acción sociopedagógica del educador social en la comunidad; Profundizar la pedagogía social y la educación social en el contexto de la intervención social escolar. Utilizamos un marco teórico-conceptual guiado por un conjunto de estudios de especialistas en pedagogía social y educación social, que nos llevó a profundizar estos conceptos en los nuevos espacios y tiempos actuales de la sociedad en general. Los espacios y tiempos de hoy marcan la Pedagogía en el ámbito social, ya sea a nivel escolar o no escolar. Sabemos que la globalización ha hecho que el "espacio y el tiempo" proliferen en aprendizajes y formas de convivencia, con nuevas características y áreas de acción o intervención. Pretendemos que la educación social incluya una serie de características de intervención, relacionadas con áreas específicas que hoy son fundamentales, además de las que su evolución e identidad han abarcado, por ejemplo: educación escolar de adultos, gerontológica e intergeneracional; el emprendimiento social; educación ambiental y ecológica; la gestión y promoción de la cultura, el patrimonio y el turismo ecológico/rural; inmigrantes, refugiados y grupos étnicos; la promoción de la mujer; mediación (escolar, social), etc.

PALABRAS CLAVE: Educación social. Intervención social y escolar. Pedagogía social. Nuevas realidades sociales. Profesión.

ABSTRACT: The article is based on the following objectives, on a hermeneutic (analytical) methodology that coincides with the structural points of the text: To analyze the indications/traces of the current reality and the direction of social education; Clarify conceptually and semantically social pedagogy and social education, in the field of Educational Sciences; Understand the (inter)relationship between social pedagogy (theoretical scope) and social education (practical scope), especially the practice of pedagogical-social action of social educators in the community; To deepen social pedagogy and social education in the context of school social intervention. We use a theoretical-conceptual framework led by a set of expert studies on social pedagogy and social education, which led us to deepen these concepts in the new spaces and current times of society in general. The spaces and times nowadays mark pedagogy in the social sphere, whether at the school and non-school level. We know that globalization has proliferated 'space and time' in learning and ways of living together, with new characteristics and areas of action or intervention. We want social education to include a series of intervention characteristics related to specific areas that are fundamental today, in addition to those that its evolution and identity have encompassed, for example: school for adults, elderly and intergenerational education; social entrepreneurship; environmental and ecological education; the management and promotion of culture, heritage and ecological/rural tourism; immigrants, refugees and ethnic groups; the promotion of women; mediation (school, social), etc.

KEYWORDS: Social education. Social and school intervention. Social pedagogy. New social realities. Profession. 


\section{Introdução}

Nas últimas décadas tem-se produzido um leque de fatores sociais, económicos, tecnológicos, culturais, políticos, etc., que implicam novas visões/enfoques para sanar necessidades e novas formas de aprendizagem diferentes, as quais sustentam novas possibilidades pedagógicas para serem satisfeitas, segundo os desafios e complexidade da sociedade (MORIN, 2001). Alguns desses fatores emergentes provocaram, por exemplo: o aumento da exigência de educação para pessoas e/ou coletivos excluídos (educação inclusiva) do sistema educativo; alterações no mercado de trabalho e empresarial que implicam novas formas de capacitação e qualificação profissional (formação contínua, reactualização); ampliação do tempo de lazer e ócio que gera necessidades de novas ações ajustadas ao âmbito socioeducativo e cultural, com novas profissões; mudanças na estrutura familiar tradicional e nas formas de vida quotidiana das pessoas que originam novas instituições que assumam funções educacionais para satisfazer a família no seu impedimento ou substituição; a sensibilidade social para intervir no âmbito de setores em conflito social, toxicodependentes, marginalizados socioeconómicos e culturais, incapacitados e deficientes, etnias e emigrantes/refugiados, como forma de justiça social e por uma funcionalidade de controlo social; etc. Tudo isto provocou, por um lado, a proliferação de novos espaços educativos inseridos na escola e/ou na comunidade e, por outro lado, a mudança na orientação do discurso pedagógico. Alguns destes discursos (pedagogia crítica) relativos à escola e ao âmbito diagnóstico do desfasamento entre sistema educativo - sistema social e mercado de trabalho, localizando as respetivas correspondências em termos sistémicos.

Paralelamente, a própria educação social (a partir de agora ES) cresce amparando-se na concepção do social, como campo de problemáticas e necessidades, que exigem intervenções na base de tratamento socioeducativo, ações de mediação e de inclusão e de transmissão cultural prática (interculturalidade), constituindo-se num serviço e num direito social de legitimação de cidadania (TIMÓTEO, 2013). Perante o cenário de mudanças e impactos, daqueles fatores na sociedade, a pedagogia social (a partir de agora PS) e a ES refletem sobre essas questões, situações e conflitos sociais humanos, sabendo que qualquer espaço no tempo(s) é próximo ao processo de aprender a aprender, propício a desenvolver capacidades ou competências nos indivíduos, com destaque para o papel das instituições educativas e da família, e, por isso, o pedagógico-social implica a necessidade atual de abertura da educação à vida em toda a sua diversidade na comunidade (NÚÑEZ, 2002). A educação de e para todos, na sua vertente cívica, 
de cidadania, afetivo-emocional, cognitiva ou simplesmente quotidiana, exige compromissos e responsabilidades para uma adequada convivência humana.

$\mathrm{Na}$ base da contextualização referida anteriormente estabeleceremos os seguintes objetivos de análise, que coincide com os dois pontos (e subpontos) estruturais do texto: Analisar os indícios/vestígios da realidades que exigem respostas no âmbito da PS e ES; Clarificar conceptual e semanticamente a PS e ES, no âmbito das Ciências da Educação, de modo a compreender o seu nível da intervenção teórico-prática; Compreender a (inter) relação entre a PS (âmbito teórico) e a ES (âmbito prático), especialmente a prática da ação pedagógicosocial do educador social na comunidade (nível relacional e convivencial); Aprofundar o papel da PS e ES (escolar), no contexto da intervenção social escolar e os desafios e respostas por parte da escola.

Servimo-nos de um quadro teórico-conceptual norteado por um conjunto de estudos de especialistas sobre PS e ES e a profissão de educação social, que nos impulsaram a aprofundar estes conceitos, a sua área e campo de intervenção teórico-prático, nos novos espaços e tempos atuais na comunidade ou sociedade em geral, sendo exemplo: os enfoques diversificados dos colegas espanhóis J.A. Caride, A. Petrus, J. Ma. Quintana-Cabanas, A.J. Colom, J. Ortega Esteban, Glória Pérez Serrano, X. Úcar, Jaume Trilla, J.V. Merino e da latino-americana Violeta Núñez; perspectiva da italiana Anita Gramigna e dos portugueses Adalberto D. Carvalho e I. Baptista, entre outros.

O nosso argumento baseia-se numa metodologia hermenêutica (analítica, crítica) à PS e ES, como argumento reflexivo para a ação ou intervenção socioeducativa, desenvolvida em territórios distintos, tendo em conta os novos espaços não-formais da educação (extraescolares) e a sua articulação com os escolares (CÁRIDE, 2005). Os espaços e tempos na atualidade marcam a Pedagogia no âmbito social, seja ao nível escolar e não-escolar e/ou comunitário. Sabemos que a globalização fez proliferar 'espaço e tempo' no aprender e nas formas de (com)viver, surgindo novas caraterísticas e áreas de ação ou intervenção, desviando o(s) discurso(s) pedagógicos da escola e centralizando-se na satisfação e necessidades sociais e culturais de formação/aprendizagem do indivíduo. Os 'novos espaços e tempos' de aprender no título estão em função do 'velho' ou habitual/tradicional espaço/tempo de aprender e, reconhecendo que eles surgiram 'devido às novas formas de aprendizagem, em contextos', com uma diversidade de meios disponíveis aos indivíduos. Ora bem, o surgimento desses 'novos espaços', quer para aprender como para intervir (processos de socialização), implica refletir sobre os tempos da Pedagogia nesses contextos ou situações formais e/ou não formais de desenvolvimento e integração do indivíduo como cidadão ativo. Neste sentido, a PS emergiu 
como uma teoria e categoria favorecedora de uma renovação de conceptualização para o currículo, os professores, os educadores sociais, educadores comunitários e outros técnicos ou profissionais (PETRUS, 2000; SAMAGAIO, 2006). Parece que aprendemos mais fora da escola e da família, confirmando aqueles pressupostos do movimento da desescolarização, na década de 70 do séc. XX (teses de I. Illich, Reimer, Holt), que reconhecia as influências educativas (boas ou más) do ambiente envolvente e dos meios tecnológicos ao dispor do indivíduo. É claro que a escola não tem que ser a única instituição ou espaço para satisfazer as necessidades de aprender, há outros espaços no tempo propícios à aprendizagem.

O nosso interesse argumentativo assenta no âmbito social e educativo/escolar. Pretendemos que a ES inclua uma série de caraterísticas, relacionadas com áreas específicas de intervenção (aspetos), como sejam (RUIZ, 2003): processuais - ações que têm o seu tempo de implementação e execução dos objetivos; educacionais - atitudes e valores promotores da autonomia, emancipação e integração e convivência comunitária; culturais - relação com o sentido de pertença e vínculo local; transformadora da comunidade - ação das pessoas/grupos para o desenvolvimento; ferramentas sociais - técnicas e estratégias de diagnóstica e de intervenção; articulação com a educação não-formal e informal (aprendizagens); abertura a alternativas perante as mudanças no seio da sociedade; orientada a todas as idades/gerações e culturas; interativa na intervenção, em que os atores sociais são os próprios protagonistas; apoio dos profissionais especializados nos âmbitos de intervenção social, escolar e comunitária.

Em definitiva, os retos da ES (vertente prática e/ou praxiológica da PS) devem integrar vários âmbitos de ação/intervenção: a animação sociocultural, socioeducativa e gerontológica; a inserção no mercado de trabalho e da formação empresarial; as crianças e/ou jovens em risco ou em perigo, incluindo o acolhimento institucional e a adoção; a marginalização, a exclusão e a delinquência infanto-juvenil; a educação escolar, de adultos e educação gerontológica (terceira idade) e intergeracional; a cooperação para o desenvolvimento local e do empreendedorismo social; da educação ambiental e ecológica (sustentabilidade); a gestão e difusão/promoção da cultura, do património e do turismo ecológico/rural; os imigrantes, os refugiados e os grupos étnicos; a promoção da mulher; a violência e maus-tratos; a mediação (escolar, social), etc. O próprio educador social hoje em dia deverá ter uma formação em banda larga, ou seja, especializada. 


\section{Indícios da realidade atual: novas exigências para novas respostas}

Nas últimas décadas as sociedades estão num processo de mudança social, em todos os setores, com destaque para os problemas da convivência e do desenvolvimento humano e vida comunitária, a ação de movimentos e redes sociais com participações específicas, a emergência de questões ambientais, socioeducativas, a transformação do mercado de trabalho, impacto das novas tecnologias na vida das pessoas, etc. Neste sentido, a educação, simultaneamente com alguma índole de crise e de aposta no futuro, constitui um dos campos de preocupação dos diversos atores, muito devido ao surgimento de novos espaços e novos tempos para aprender a aprender, novos discursos que implicam novas perguntas conceptuais, pedagógicas e metodológicas para enfrentar essas mudanças, em especial na escola. No seguimento destas alusões anteriores destacamos alguns indícios ou vestígios na sociedade que pressionam as instituições educativas e a própria educação e pedagogia em si mesma e que obrigam a procura de (novas) respostas da escola e da comunidade (MORIN, 2001).

Devemos aludir, logo de entrada, que a eclosão da educação social coincidiu com essas transformações, por exemplo: de índole económica (economia de produção, revolução tecnológica, reconversão e especialização profissional) produzindo bolsas de pobreza, excluídos, marginalizados e desprotegidos necessitados de intervenção; de índole relacional e de organização social (quebra das redes tradicionais de comunicação e de relação, produzindo o efeito 'cocoon'); e de índole axiológico (valores de consumo, de solidão, individualismo, violência e transgressão dos direitos humanos como expressões espontâneas, o desaparecimento dos referentes tradicionais familiares, a perda do sentido coletivo e de ação do grupo, a indiferença e a ansiedade perante as mudanças sociais) (QUINTANA-CABANA, 2001). Estas alterações contribuíram para que a PS e a ES interviessem nesses setores de excluídos e incapazes de inclusão e adaptação, com especial menção no contexto escolar (pedagogia social escolar).

Vejamos alguns desses indícios existentes na sociedade que desafiam a procura de respostas e medidas nos tempos atuais por parte da PS e da ES e/ou da intervenção.

-Indício 1: Manifestações, supostas ou controversas na sociedade sobre a educação, que pressionam as instituições escolares e a própria educação e pedagogia, por exemplo:

Uma sociedade exigente na educação e/ou na formação (qualidade e excelência), mas não no âmbito prático. 
A escola sendo cada vez mais inclusiva não realiza novas tarefas facilitadores, pois o seu modelo organizacional contínua invariável, tal como os modelos de avaliação da aprendizagem.

As famílias apresentam um diálogo e cooperação escassa com a escola na resolução dos problemas escolares, devido à mudança nas estruturas familiares, surgimento de novas diversidades culturais e sociais, ocupação e compromissos laborais e indisponibilidade de tempo que a impedem de envolver-se em projetos e programas educativos e parentais, já que delegam essa ação à escola.

$>\quad$ Os professores mesmo realizando novas funções mantêm, em geral, os mesmos esquemas tradicionais na organização e gestão do seu trabalho escolar.

As novas gerações de alunos mudam, mas o estilo e a metodologia de ensino pouco se alteram (não ajustável às necessidades e exigências), mesmo com o contributo das novas tecnologias no ensino-aprendizagem.

De facto, as instituições educativas/escolares intentam dar resposta a esses e outros problemas que a sociedade atual gera, incutindo atitudes e comportamentos perante situações como: o insucesso, o abandono (precoce), a violência (bullying) e indisciplina escolar; a xenofobia e o racismo; o consumo exacerbado; a falta de controlo e gestão emocional; os elevados acidentes de trânsito na população juvenil; as alterações do meio ambiente; as epidemias e pandemias (educação para a saúde), etc. Parece que mediante um certo desconcerto da educação e da escola em formar para a cidadania global e cosmopolita seja necessário: reconhecer que a escola, mesmo cumprindo as suas funções e resolvendo problemas práticos da vida quotidiana escolar, deve adaptar-se às novas realidades entroncadas na componente educativa formal e não-formal; ter em conta a diversidade e a mutabilidade do mercado laboral, cada vez mais exigente na qualificação e especialização profissional; redefinir as possibilidades da educação escolar como instrumento para a igualdade social, já que a escola promove a cultura e a emancipação individual; rever a relação escola-família mobilizando um maior envolvimento nas tarefas educativas e nos projetos escolares; reconsiderar o papel da competência mediática valorizando a utilidade dos meios de comunicação, os meios digitais e outros meios tecnológicos; reconsiderar os modelos de sentimentalidade transmitida, já que as estratégias emocionais dadas correspondem a formas relacionais e dependência social superadas; insistir na inclusão e na interculturalidade. 
Perante estes cenários é preciso uma redefinição dos limites da ação educativa, condição indispensável a que a escola promova os seus âmbitos de cooperação e colaboração com a comunidade, a família e as instituições sociais (COLOM, 1987).

-Indício 2: Contradições e dilemas sobre a escola. Pensamos que existe no seio da escola a necessidade de uma reconstrução adequada aos novos tempos, já que ela não apresenta respostas e medidas (projetos, programas) eficazes para situações e problemas práticos da vida quotidiana dos alunos em formação (TIMÓTEO, 2013). Ou seja, a escola deve renovar-se e adaptar-se às suas funções reais, por exemplo: articulando a perspetiva formal e não formal do ensino-aprendizagem (TRILLA; GROS; LÓPEZ; MARTÍN, 2003; TROTTER, 2015); adotando medidas eficazes (mediação) para com as situações de violência e indisciplina escolar, inadaptação social (VARGAS, 1998) e para questões de não-inclusão, da diversidade cultural (inter e multiculturalidade); promoção da educação parental; adequar-se às exigências do mercado laboral, através de uma formação profissional mais efetiva (orientação, qualificação); ampliar as possibilidades da educação escolar como instrumento para a igualdade social (âmbito da cultura e emancipação); rever a relação da 'escola-família' num maior envolvimento no processo educativo dos alunos; aprofundar a relação 'escola-meios de comunicação' (competência mediática); reconsiderar os modelos de sentimentalidade, insistindo em outras estratégias afetivo-comportamentais e de desenvolvimento de habilidades sociais e emocionais, etc. Nesta renovação da escola, a educação social é preponderante no âmbito da ação educativa e/ou intervenção socioeducativa, promovendo áreas de colaboração com a comunidade; reforçando e desenvolvendo a aquisição de (novas) competências básicas e metodológicas essenciais aos alunos (aprendizagem autónoma, educação emancipatória e 'empowerment') e, ainda na compreensão da realidade atual (educação ambiental) e de pandemia (educação para a saúde), como a que atravessamos.

Nesta perspetiva de limitação do papel da escola deve-se ter em conta as medidas (programas, projetos) de integração e inserção de diversos coletivos de crianças e jovens em risco, de modo a permitir a sua convivência real na comunidade (modelo de relação social ativo e participante) e a inclusão. Desta maneira, a escola definirá as suas funções sociais na construção de uma nova cultura escolar baseada na colaboração com outras instituições sociais, com a família e a comunidade (CAPUL; LEMAY, 2003). Por isso, é desejável a construção de uma pedagogia (social) escolar na relação entre 'escola-educação social' assente na tríade: formação de professores e profissionais conhecedores das novas realidades (socialização) e da cultura escolar (problemas); dar respostas e implementar medidas orientadas à convivência e para a construção de uma cidadania ativa, na base da orientação e mediação socioeducativa na 
resolução de conflitos; fomentar o trabalho cooperativo entre os profissionais (equipas multiprofissionais) no seio escolar, em sintonia com os técnicos do município e das instituições da comunidade, no âmbito da prevenção e da promoção educativa e cultural (AZEVEDO et al., 2014). Perante estes supostos indicados apostamos, ao nível da ação/intervenção escolar e social, pelo processo de institucionalização da PS e da ES ao nível escolar (CÁRIDE, 2003; COLOM, 1983).

-Indício 3: novos discursos pedagógicos para reformar, modernizar e readaptar os sistemas educativos e colmatar os desafios da sociedade (digital) cada vez mais complexa e tecnológica (MORIN, 2001). A modernização e avanços tecnológicos determinam a participação ativa da escola, da família e de outras instituições da comunidade. Desta amálgama de discursos apareceram 'novos' conceitos relacionados com a pedagogia, como a educação de adultos e/ou permanente, a educação informal e não formal, a andragogia, a educação inclusiva, a sociedade educativa ou sociedade de aprendizagem (cidade educativa), a educação intergeracional, etc. Esta proliferação conceptual associada à pedagogia partilha basicamente dois princípios gerais: a heterogeneidade (a educação é um fenómeno amplo, complexo e heterogéneo) e a globalidade (visão holística do processo educativo). É nesta perspetiva (global e integradora) de que todas as educações se misturam e se entrelaçam na educação do educando e que devem ser entendidas pelas instituições educativas (RUIZ, 2003). Ora, isto implica o paradigma do meio educativo, em que toda a ação educativa se entende como relacional em meio/situação ou contexto determinado, seja na escola, família ou comunidade, sabendo que o meio influencia/condiciona e configura a relação educativa (educador-educando) e associa-se a outros elementos determinantes (novas tecnologias, meio ambiente, aprendizagens não formais)

É evidente que a educação não escolar é muito ampla, com um repertório que vai desde a vertente: da formação ocupacional e profissional e/ou em contexto empresarial (estágios profissionais), programas de qualificação e profissionalização (reconversão); vertente do tempo livre (ócio, lazer) e da cultura (animação sociocultural, animação socioeducativa e comunitária); vertente da educação social nas instituições educativas na resolução de problemas (conflitos sociais); vertente escolar com programas/projetos de envolvimento escola-família e comunidade; vertente da intergeracionalidade e multiculturalidade com ações e programas envolvendo diferentes gerações e culturas. Cremos que este leque de educações e pedagogias primam pelo desenvolvimento da sociabilidade do(s) indivíduo(s), em especial os grupos de conflito ou risco social e em contextos ou meios de educação não-formal e formal (ÚCAR, 2013). 


\section{Novos tempos e novos espaços da pedagogia social versus educação social}

Neste ponto de abordagem devemos logo de início explicar a identidade e evolução da 'Pedagogia' e a sua aproximação ao 'social', convertendo aquela área numa ciência social e pedagógica, de caráter normativo (valores), ao propor fundamentos teóricos explicativos dos processos práticos de intervenção socioeducativa e sociocultural, que no fundo é a dimensão da educação social (MARTIN, 2009). Ou seja, a Pedagogia mantém a sua identidade como uma área científica independente das outras ciências, tendo na 'normatividade' o princípio irrenunciável da sua justificação epistemológica, já que tem a possibilidade de elaborar normas educativas com suporte científico que the proporcionam às Ciências da Educação, com capacidade de validar cientificamente essas normas (autonomia como ciência) (MERINO, 2005).

De facto, a realidade educativa e comunitária fez eclodir da PS e/ou da ES múltiplas atividades e intervenções distintas, elencadas na confluência do 'educativo e/ou pedagógico' e do 'social', muito devido às origens, identidade e desenvolvimento histórico dessas áreas (CARIDE, 2005). Enquanto o 'pedagógico' revela certa inspiração de recuperação do sentido da 'paideia' grega de uma educação ao serviço das pessoas e do seu próprio desenvolvimento, o 'social' expressa a sensibilidade da educação para as necessidades de todos, principalmente dos grupos que estão marginalizados, excluídos, em condições precárias de vida e de inadaptação (ORTEGA ESTEBAN, 2005). Sabemos que são as necessidades práticas que configuram a reflexão teórico-prática da conceptualização e paradigmas, da metodologia de intervenção e técnicas de investigação da PS e ES (PÉREZ SERRANO, 2004).

Historicamente, desde os inícios do século passado, a Pedagogia avançou para a sua caraterização como ciência de abordagem à educação, como construção histórica e social, que apresenta as suas convergências com outras ciências sociais e humanas (antropologia, sociologia, história, economia, direito, psicologia, entre outras) (CARIDE, 2003). Assim, a PS, desde Paul Natorp, que o 'social' da educação e da pedagogia necessitou muito tempo para renovar a conceção pedagógica sobre as condições sociais da educação e da vida social e, por isso, no dizer do professor da Universidade de Santiago Compostela J. A. Caride (2009), todas as pedagogias e as suas educações são sociais e entrelaçadas nas fronteiras da teoria e da práxis socioeducativa. Nessas fronteiras as redes tecnológicas submeteram a PS à renovação, fazendo emergir a ES no âmbito dos serviços sociais e das políticas sociais e culturais (TRILLA, 2000). Neste sentido, muitas dessas formalidades reclamaram para si a OS, originando-lhe a construção de sinais de identidade como ciência, como área científica e como profissão. Ou

RIAEE - Revista Ibero-Americana de Estudos em Educação, Araraquara, v. 15, n. esp. 3, p. 2167-2187, nov., 2020. e-ISSN: 1982-5587 
seja, elencou-se no âmbito da teoria-prática, da reflexão-ação e no campo científico, académico e profissional (CARIDE; GRADAÍLLE; BELÉN CABALLO, 2015).

Mas como definimos ou o que é a PS e a ES?

A PS tem como objeto a ES (socialização do indivíduo) e o trabalho social (ajuda, apoio a necessidades humanas e sociais) (DIÁZ, 2006). Ambos os termos, em várias ocasiões, utilizam-se indistintamente. Enquanto a PS é a ciência da educação social (mais teórica) ao indivíduo/grupo na atenção aos seus problemas e necessidades (humanas, sociais, educativas), a ES constitui o âmbito de intervenção ou ação (prática) na resolução daqueles problemas ou necessidades existentes (políticas sociais) (QUINTANA-CABANAS, 2001). Portanto, a PS implica conhecimento, ação e técnica ou tecnologia necessária para a educação de pessoas e grupos em situações de marginalização, precariedade, exclusão e de conflito social e, por isso, designa-se como: pedagogia da socialização (aborda a integração epistemológica, tecnológico e normalizado); pedagogia da inadaptação e da marginalização; e pedagogia especializada (ORTEGA ESTEBAN, 1999). Estas vertentes, de índole pedagógico-social constituem uma constante no desenvolvimento de novos cenários de intervenção, configurando-se a PS como uma ciência pedagógica que criou um corpus de conhecimento próprio preocupada pela dimensão social da educação (SILVA et al., 2011).

Por conseguinte, a PS deve ser entendida como ciência da educação social ao abordar e analisar questões inerentes à socialização dos indivíduos nos novos cenários sociais, como seja a inadaptação e exclusão, orientando-se para a sua inclusão e melhoria das condições de vida, numa perspetiva especializada e prática. Ou seja, o objeto da PS é a ES ou a ação/intervenção pedagógico-social ou socioeducativa, uma vez que ela é a teoria e prática da ES (NÚÑEZ, 1999). O socioeducativo e/ou o pedagógico-social insere-se no âmbito (educativo) da sociedade e no pedagógico do trabalho social e, por isso, a melhoria ou a transformação de uma determinada realidade/comunidade realiza-se com uma "[...] intervenção processual, no sentido de processo" (o grifo é nosso) técnico-sistémico (= ciência e tecnologia do fenómeno e intervenção socioeducativa) (ORTEGA ESTEBAN, 1999, p. 23). Assim, a orientação crítica da PS orienta-se para posições dialéticas ou hermenêutico-dialéticas, da sociologia crítica, da pedagogia social crítica e emancipatória de Mollenhauer, de alguns aspetos do construtivismo, da teoria dialógica de Habermas, das teorias da comunicação, etc. (NÚÑEZ, 2002; VARGAS, 2008).

Vejamos nos dois pontos seguintes a origem, a evolução e identidade da PS e o(s) âmbito(s) de intervenção social e/ou socioeducativa da ES para melhor compreendermos a importância da PS nos novos espaços e tempos da atualidade. 


\section{A pedagogia social/educação social: Das origens à identidade}

Para compreendermos a construção científica e a intervenção prática da PS e da ES convém referirmos à origem, evolução, identidade e tendências prospetivas e metodológicas, destas áreas, na base de diversos estudos (BAENA; SÁENZ; QUINTANA-CABAÑAS, 2002; GRAMIGNA, 2003; PÉREZ SERRANO, 2004).

1-Origem alemã e difusão no centro de Europa (séc. XIX no Pós II Guerra Mundial). Trata-se duma vertente idealista e conceptualista que relaciona o significado de 'pedagogia' com 'pedagogia social', gerando o vínculo entre PS-ES (esta é o campo e objeto de estudo da pedagogia social). As finalidades desta pedagogia são de índole social, política e filosófica, impregnada de influências do sociologismo e culturalismo de Natorp e H. Nohl, pois orientase à educação social da juventude, ao seu bem-estar e proteção que, mais tarde, se designou por 'Pedagogia de Urgência' no após II Guerra Mundial (PETRUS, 1997). Superadas as influências empírico-positivistas, relacionadas com a psicologia e a sociologia, deu-se a separação entre a PS e o 'trabalho social'. Assim, a PS integrou a dialética da sua teoria e prática no seio do trabalho social, diversificando-se em funções e tipos de instituições. Mais tarde, esta vertente derivou-se do racionalismo crítico (Popper, Topitsch) para outras tendências, tais como a vertente tecnológica ou sistémico-empirista (Brezinca, Rössner), em que se convergiu o 'trabalho social' e a PS (NÚÑEZ, 1999). Esta tendência foi seguida na Alemanha, Suíça, Áustria, Holanda e Dinamarca, com as suas peculiaridades.

2-Origem e influência anglo-saxónica. Trata-se de uma tendência filosófica, positivista e empirista, divulgada nos EUA, Inglaterra ('Social Work') e, depois, na Europa, integrando a análise às carências e dificuldades sociais e humanas, feita a partir da sociologia (sociologia da educação), da psicologia (social), medicina e/ou psiquiatria. Expressa uma perspetiva assistencialista (ajuda, planificação e gestão), que menciona pouco o conceito Pedagogia e muito menos o de PS, apesar do 'educativo'/'pedagógico' estar unido ao 'trabalho social' (CARIDE, 2005). Os seus campos de intervenção são: os sujeitos excluídos, inadaptados e antissociais; os menores em conflito (delinquência, marginalização, exclusão); infância/juventude e sujeitos carenciados (biopsicológicos). Os modelos de intervenção baseiam-se no tratamento clínico, psico-psiquiátrico, reeducativo e/ou médico-pedagógico ao nível institucional (cárceres, asilos, reformatórios, colónias correcionais, instituições específicas) (PÉREZ SERRANO, 2004). Os serviços sociais são contributos do sistema social e assistencial para colmatar essas situações de risco e de exclusão (GRAMIGNA, 2003).

RIAEE - Revista Ibero-Americana de Estudos em Educação, Araraquara, v. 15, n. esp. 3, p. 2167-2187, nov., 2020. e-ISSN: 1982-5587 
3-Origem e influência francófona. Tendência assente numa tradição racionalista em vários países europeus ao destacar a análise política e sociológica do sistema escolar e da institucionalização educativa (ativismo pedagógico, democratização do ensino, educação cívica e para a cidadania), a partir da educação popular, educação de adultos e, posteriormente, da animação sociocomunitária ou sociocultural. Este tipo de ES evoluiu ao longo do séc. XX, na sua vertente benéfico/assistencialista, com uma orientação benemérita, filantrópica e pestalozziana (séc. XIX), nos seus enfoques protecionistas e psicopedagógicos, tendo originado várias iniciativas formativas, de profissionais e associações (CAPUL; LEMAY, 2003). A própria orientação da animação foi-se implementando paulatinamente ao nível da formação de técnicos ou cursos de licenciaturas (SERAPICOS; SAMAGAIO; TREVISAN, 2011). Esta origem francófona associou-se a algumas ideias anglo-saxónicas, as quais tiveram repercussão e influência em Portugal (AZEVEDO et al., 2014).

4-Origem e influência da pedagogia crítica. A teoria crítica com seu carácter reflexivocrítico influenciou a PS (referência a Mollenhauer) e estabeleceu uma ponte entre a educação e a estrutura e contexto social e, ainda, aprofundou os valores inerentes às instituições educativas, no modo de pensar/analisar a realidade envolvente (enfoques, perspetivas) (DIÁZ, 2006). Neste sentido, a pedagogia crítica, sendo comunicativa e consensual (modelo ecológico), utilizou a investigação como estratégia metodológica, dando relevância às diferenças culturais. Ora, esta estratégia remeteu-se para a memória histórica, para a autocrítica e reflexão dos coletivos, na intenção de valorizar a prática e analisar criticamente os conflitos irracionais, com uma dialética (teoria-prática) que é relacional, contextual, situacional e intersistémica. Ou seja, a pedagogia social crítica passou a abordar e analisar os aspetos económicos, sociais e políticos referentes às problemáticas infantojuvenis, de coletivos específicos, grupos étnicos, imigrantes e refugiados, na pretensão da sua adaptação, inserção, socialização e reeducação para a sociedade. Assim, a sua tarefa socioeducativa consiste em procurar respostas às necessidades sociais e educativas provocadas pela sociedade e, por isso, pretende a emancipação humana e a análise das estruturas sociais, com a finalidade de as melhorar e transformar (CARIDE; GRADAÍLLE; BELÉN CABALLO, 2015).

Efetivamente, a PS apresenta-se nessa evolução histórica e de consolidação da sua identidade, por um lado, com um caráter teórico-prático, já que frequentemente a prática se antecipa à formulação teórica, devido à tipologia das necessidades e problemáticas existentes (coletivos, indivíduos), em diversos contextos, o que implica ser uma vertente especulativa da própria práxis (SILVA, 2009). Por outro lado, têm um caráter normativo que advém de ser uma ciência pedagógica que abarca várias temáticas educativas. Além disso, a polissémica do termo 
ES e a amplitude das suas áreas ou campos teórico-práticos, a que fizemos referência anteriormente, torna difícil de conformar um suporte epistemológico da conceção da PS (PETRUS, 1997). Dito de outra maneira, podemos entender a ES desde a teoria pedagógica, no momento de limitarmos o seu marco conceptual (semântico) e tendo em conta as suas origens históricas (QUINTANA-CABANAS, 2001) e, por isso, pode ser compreendida como: conceito sociologista da educação sendo o meio de adaptação do indivíduo à sociedade no desempenho do seu papel social (Durkheim, Natorp, Kerschensteiner, Kieck, Dewey); formação do indivíduo no processo de socialização e na formação básica e contínua do indivíduo na perspetiva de 'aprender a aprender' (educação cívica, para a cidadania, para a convivência e solidariedade, para a paz, respeito e tolerância) no contexto democrático e na diversidade cultural (interculturalismo); forma de trabalho social referida como área especializada na intervenção com certos coletivos (crianças/jovens em risco, marginalizados e excluídos, toxicodependentes, emigrantes, refugiados, pessoas/grupos vulneráveis ou em precariedade na sociedade), que são os sujeitos da ação socioeducativa da ES (THOMPSON, 2009; TROTTER, 2015).

Portanto, a ES constitui um conceito amplo e integrador da educação para a cidadania, o civismo e a política democrática, no âmbito duma formação integral da pessoa. Ela orientase ao indivíduo/grupos inseridos na comunidade, em que a sua ação ou "[...] intervenção da educação e pedagogia social é o próprio social" (ORTEGA ESTEBAN, 1999, p. 26, grifo nosso). De facto, é o social que emerge no campo da convivência e das relações, na equidade, na comunicação relacional das pessoas e grupos, de tal modo, que elenca um repertório de aplicações práticas essenciais à formação do indivíduo, no sentido social e das relações humanas. Daí que a tarefa da ES seja a inserção/inclusão dos indivíduos no seu meio (comunitário), procurando o sentido ético-cívico e empreendedor, proporcionando-lhes uma consciência adequada aos vínculos que os unem à comunidade, com uma conduta correta e de cumprimento dos direitos no campo social, de modo a serem capazes de melhorar e transformar a sociedade. A finalidade da ES assenta nesse amadurecimento social e moral do indivíduo, na promoção das suas relações humanas e na preparação para conviver com os outros na sociedade (TIMÓTEO, 2013). Hoje em dia, a ES preocupa-se, para além da educação das pessoas adultas e idosas (gerontologia), pela animação sociocultural ou socioeducativa, pelo desenvolvimento comunitário, por uma educação personalizada e especializada, que abarque a educação intergeracional e/ou a educação ao longo da vida para todas as gerações e idades (ORTEGA ESTEBAN, 2005). 
$\mathrm{Na}$ verdade, a ES apresenta um leque de enfoques e perspetivas, como sejam por exemplo (PETRUS, 1997): a adaptação, a socialização, a aquisição de competências sociais, a didática do social, a ação profisssional qualificada (especialização), as respostas às inadaptações sociais, formação do cidadão (global e cosmopolita), na prevenção e controlo social e, ainda como trabalho social, de âmbito socioeducativo e como educação não formal e/ou extraescolar. Apesar desta panóplia de formas de entender a ES, as teorias generalizáveis, com recurso às suas origens e antecedentes históricas, consideram-na (MARTINS, 2013; GRAMIGNA, 2003) como: orientada à mudança social tornando protagonistas os próprios destinatários; socializadora ao pretender a adaptação social; inserida no seio dos problemas humanos e sociais; aplicada habitualmente nos contextos não formais da educação, mas também nos escolares; priorizando o seu campo de ação na marginalização, exclusão social e na prevenção e proteção infanto-juvenil; exige um contacto assíduo dos indivíduos e grupos com a realidade envolvente, utilizando uma intervenção qualificada ou especializada (educação social especializada) (ORTEGA ESTEBAN, 1999). Estas ações de diversa índole, presentes ao nível comunitário e na sociedade com as suas lacras (marginalização, pobreza, violência, exclusão, inadaptação, falta de inclusão), permite à educação social tomada de medidas socioeducativas preventivas e inovações para a melhoria da qualidade de vida e formação das pessoas, para o desenvolvimento social e comunitário (RUIZ, 2003). Assim, a ES, nas suas várias correntes e conceções, deve ser considerada necessária e útil à integração, inclusão e desenvolvimento social das pessoas/grupos, em especial os mais vulneráveis (CARVALHO; BAPTISTA, 2004).

\section{A educação social como âmbito de intervenção social e educativa}

Em termos de intervenção a ES abrange quatro grandes pilares, como são (TRILLA, 2000): a área sócio-assistencial, correspondente às situações/problemas de vida de pessoas/grupos e/ou famílias, que exigem uma ação imediata dos profissionais em termos de ajuda, acompanhamento, auxílio e interajuda, sendo um bom exemplo muitas organizações, por exemplo a Cáritas e Organizações Não governamentais; a área socioeducativa com processos facilitadores de integração e/ou melhoraria da vida de pessoas/grupos, promovendo modificações de atitudes e comportamentos, valorizando novos valores (cívicos, ético-morais) desejáveis à formação do cidadão (global, cosmopolita); a área sociocultural referente à promoção, divulgação, gestão e desenvolvimento de todas as dimensões de cultura (em especial a patrimonial), mas a partir da ação e protagonismo dos coletivos/grupos sociais; a área socioeconómica para o desenvolvimento local, incidindo nos aspetos referentes ao desemprego 
e emprego temporário, à promoção do autoemprego e empreendedorismo, o cooperativismo ao nível comunitário (aproveitamento dos recursos locais) e dando uma atenção especial aos grupos desfavorecidos e excluídos; a área da inter e transgeracionalidade, promovendo o intercâmbio de saberes, experiências e vivências entre gerações; na participação ativa dos idosos ao nível da cidadania e desenvolvimento e na aprendizagem (gerontologia educativa), tendo um papel importante a animação (sociocultural, socioeducativa).

De qualquer forma a intervenção e os seus limites no campo de ação dos profissionais da ES (educador social) faz que estes dominam uma variedade de recursos com intuito dar resposta às situações diversas e de conflitos sociais (e escolares) existentes, diagnosticando, programando e planificando projetos (modelos, uns mais globais e polivalentes, outros mais específicos) na prática, especialmente relacionados com as políticas sociais e/ou serviços sociais, mas também ao nível do contexto escolar (AZEVEDO et al., 2014; SILVA, 2009). Ora bem a ES, a partir da sua orientação prática, utiliza métodos complexos de intervenção (Casework, Groupwork - Social groupwork e trabalho comunitário - community work, Gemeinwesemarbeit), cada um com técnicas específicas e diferenciadas, por exemplo: preventivas de índole ambiental, de ajuda; de índole terapêutico, orientadas a trabalhar o currículo social na escola; de resolução de conflitos, através da mediação social e escolar, tendo em conta cada caso e situação de intervenção (PÉREZ SERRANO, 2004).

De facto, devido às transformações sociais, económicas, à turbulência e exigências do mercado de trabalho, as sociedades apresentam uma complexidade no seu funcionamento e, por isso, a intervenção social (e escolar) é fundamental na extensão e garantia dos direitos sociais e cívicos (SILVA et al., 2011). Ora, essas intervenções são insuficientes devido à contingência, à mudança de valores e formas de vida das pessoas, o que obrigam a novas formas de ação/intervenção dos profissionais da ES, os quais atuam em setores emergentes, como (SERAPICOS; SAMAGAIO; TREVISAN, 2011): as questões de género (mulher) e do espaço social; dos idosos e relações intergeracionais; nas problemáticas de desemprego, nas novas bolsas de pobreza e exclusão social; nas situações da inter e multiculturalidade; na participação cidadã e empowerment; na solidariedade (geracional, relacional) ao nível comunitário; na mobilidade de pessoas e trabalhadores, em especial a imigração e refugiados; na diversidade de situações de violência, violações, xenofobismo e racismo; nas mudanças nas relações pessoais e de grupo; etc.

Por conseguinte, a ES tem um papel fundamental no desenvolvimento e intervenção em diversos grupos/coletivos, especialmente na vertente socioeducativa, na procura implementar a igualdade de oportunidades na sociedade, na mudança de perspetiva e imagem social do 
indivíduo (em especial a mulher) e incrementar mais a solidariedade e inclusão (VARGAS, 1998). Por isso, no âmbito da OS, a ES constitui o eixo condutor para o desenvolvimento de atitudes positivas e solidárias entre todos os cidadãos, independentemente do sexo, idade, cultura, religião ou geração. Ora a intervenção social e educativa deve ser feita ao nível comunitário para favorecer o seu desenvolvimento e o bem-estar, mas com recurso a vários âmbitos da PS (animação sociocultural, socioeducativa, gerontológica; pedagogia participativa e comunitária; educação dos adultos e educação intergeracional), de modo a responder eficazmente com medidas de melhoria e adequação das pessoas e coletivos à sua própria vida.

\section{Algumas ideias (IN)conclusivas e para reflexão}

Sabendo que a educação é um importante referente na atual sociedade, pois aprendemos ao longo da vida; por vezes sucede que de tanto olhar no retrovisor não prestamos a devida importância aos problemas ou realidades, nestes novos tempos com novos espaços que apareceram e mexeram no modus de vida, nas relações, na comunicação e na convivência das pessoas e grupos. Não podemos reduzir a educação à vertente escolar, pois hoje em dia aprendemos em diversos contextos e (novos) espaços não escolares (educação não formal onde se insere a educação social). É evidente que a educação é global, é social e realiza-se ao longo da vida (lemas da Unesco: 'aprender a aprender' e a aprender a viver juntos) (TRILLA et al., 2003). Se o objetivo da educação é capacitar e resolver situações/problemas das pessoas e grupos para viver na sociedade, comunicando-se e relacionando-se, a educação facilita a formação dos cidadãos nas competências sociais necessárias para descobrir a (nova) realidade (exemplo a atual pandemia) e os direitos dos outros.

Referimos ao longo do texto que a PS se orienta à reflexão sobre a 'intervenção' ou 'ação' (componente teórica) de situações sociais/culturais e circunstâncias que as originam, servindo-se da ES (objeto daquela e a ação na prática) para esse vínculo com a realidade e respetivas narrações (atividade de emancipação e desenvolvimento humano) (CARIDE, 2005). Entendemos a ES como a ação promotora e dinamizadora de uma sociedade que educa e de uma educação integral, que ajuda/apoia, mediante a educação, de modo a evitar ou reparar dificuldades e conflitos sociais (RUIZ, 2003). Ou seja, ela procura nos novos cenários respostas incisivas sobre os problemas humanos e sociais (exclusão, marginalização, inadaptados ou não inclusivos) na sociedade atual, prevenindo as suas causas. Daí a ES integrar áreas ou campos de ação relacionados com os tempos livres e o ócio (infância, juventude, adultos), a educação 
de adultos e permanente (e terceira idade), a animação sociocultural e gerontológica e a educação especializada (ORTEGA ESTEBAN, 1999).

Por outro lado, a PS deve colaborar com a escola e os seus problemas, de modo a confluir energias, estratégias e processos entre a 'Escola-Família-Comunidade' e outros microssistemas comunitários, em tarefas de mediação, situações de conflito e violência, inadaptação, disfuncionalidade, relações de convivência, abandono e insucesso escolar, dificuldades de adaptação, às formas de analfabetismo emotivo, etc. (VIEIRA, 2013). Haverá que dar mais atenção àquelas em contexto escolar e às exigências da cultura escolar, já que a ES e a educação escolar não são realidades opostas, pois a realidade é única. A própria OS, ao enveredar para o escolar, fez emergir um (novo) espaço de intervenção prática da ES, na prevenção e tratamento de situações específicas (CARÍDE, 2015; NÚÑEZ, 2002). Assim, têm surgido vários campos de intervenção à ES, com implementação de projetos e criando redes sociais informativas (projeto comum de cidadania), destacando os seguintes aspetos: favorecer a construção da comunidade interativa e intergeracional, com especial atenção à terceira idade e à intergeracionalidade na realidade social; aos espaços de encontro, de intercâmbio e promoção de convivência no âmbito inter/multicultural em prol de uma cidadania (global e cosmopolita) na diversidade; em novas atividades físicas, recreativas e desportivas, que são fatores de socialização e de bem-estar para a saúde dos indivíduos; nas problemáticas dos imigrantes e refugiados na sua integração na sociedade de acolhimento; nos propósitos da escola inclusiva com alunos com dificuldades de adaptação; numa educação especializada à educação das pessoas adultas e no âmbito empresarial; na criação de consciência de educação ambiental ao nível planetário, etc. Todas estas novas situações merecem uma reflexão-açãoreflexão dos profissionais da ES ao nível da intervenção (novos modelos), contribuindo com a mediação na integração do indivíduo nos novos tempos e novos espaços que surgem na sociedade.

Por conseguinte a PS - ES constituem uma 'práxis' quotidiana nos contextos socioeducativos formais e não formais, especialmente na relação 'Escola-Comunidade', mas para tal efetividade exige-se mudanças nos estilos dos professores e nos modelos organizativos da escola, gerando-se uma estreita colaboração entre o educador social e os outros técnicos ou profissionais que atuem em prole de uma aprendizagem social. 


\section{REFERÊNCIAS}

AZEVEDO, S.; CORREIA, F.; DELGADO, P.; MARTINS, T. A educação social em Portugal: novos desafios para a identidade profissional. Interfaces Científicas Educação, Aracaju, v. 3, n. 1, p. 113-124, 2014. DOI: https://doi.org/10.17564/23163828.2014v3n1p113-124

BAENA, M. P. L.; SÁENZ, J. M. M.; QUINTANA-CABAÑAS, J. M. Pedagogía social. Madrid: Publ. Uned, 2002.

CAPUL, M.; LEMAY, M. Da educação à intervenção social. Porto: Porto Editora, 2003. v. 1.

CARIDE, J. A. Elogio de la pedagogía social: acerca de los nuevos y viejos desafíos de la educación social. Praise of Social Pedagogy: about the new and old challenges of social education. Revista de Educação Pública, Cuiabá, v. 18, n. 38, p. 449-468, 2009. DOI: https://doi.org/10.29286/rep.v18i38.391

CARIDE, J. A. Las fronteras de la pedagogía social. Perspectivas científica e histórica. Barcelona: Gedisa, 2005.

CARIDE, J. A. Las identidades de la educación social. Cuadernos de Pedagogía, n. 321, p. 47-51, 2003.

CARIDE, J. A.; GRADAÍLLE, R.; BELÉN CABALLO, M. De la Pedagogia social como educación, a la educación social como Pedagogía. Perfiles Educativos, México, v. XXXVII, n. 148, p. 4-11, Suplemento 2015. Disponível em:

http://www.scielo.org.mx/pdf/peredu/v37n148/v37n148a16.pdf. Acesso em: 10 set. 2020.

CARVALHO, A. D.; BAPTISTA, I. Educación social. Fundamentos e estratégias. Porto: Porto Editora, 2004.

COLOM, A. J. et al. Modelos de intervención socioeducativa. Madrid: Narcea, 1987.

COLOM, A. J. La pedagogia social como modelo de intervención socioeducativa. Bordón, Madrid, n. 247, p. 165-180, mar./abr. 1983.

DIAZ, A. S. Uma aproximação à pedagogia. Revista Lusófona de Educação, Lisboa, n. 7, p. 91-104, 2006.

GRAMIGNA, A. Manuale di pedagogia sociale (Scenari del presente e azione educativa). Roma: Armando Editore, 2003.

MARTIN, R. L. Fundamentos políticos de la educación social. Madrid: Ed. Síntesis, 2009.

MARTINS, E. C. A Pedagogia social/Educação social nos meandros da comunidade e da escola. Educare et Educere, Portugal, v. XV, n. 1, p. 5-24, 2013. 
MERINO, J. V. Pedagogía social y educación social: Reto de conocimiento y de acción para el siglo XXI. In: RUIZ BERRIO, J. (Ed.). Pedagogía y educación ante el siglo XXI. Madrid: Publ. Universidad Complutense Mafrid, 2005. p. 225-251.

MORIN, E. O desafio do Século XXI. Religar os conhecimentos. Lisboa: Instituto Piaget, 2001.

NÚÑEZ, V. (Coord.). La educación en tiempos de incertidumbre: las apuestas de la Pedagogía Social. Barcelona: Gedisa, 2002.

NÚÑEZ, V. (Coord.). Pedagogía social: cartas para navegar en el nuevo milénio. Buenos Aires: Santillana, 1999.

ORTEGA ESTEBAN, J. La educación a lo largo de la vida: la educación social, la educación escolar, la educación continua... todas son educaciones formales. Revista de Educación, Madrid, n. 333, p. 167-175, 2005.

ORTEGA ESTEBAN, J. Pedagogía social especializada. Pedagogía de menores en dificultad y en conflicto social. Barcelona: Ed. Ariel, 1999.

PÉREZ SERRANO, G. Pedagogía social - educación social. Construción científica e intervención práctica. Madrid: Narcea, 2004.

PETRUS, A. Nuevos âmbitos en educación social. In: ROMANS, M.; PETRUS, A.; TRILLA, J. De profesión: educador(a) social. Barcelona: Paidós, 2000. p. 63-147.

PETRUS, A. Pedagogía social. Barcelona: Ariel, 1997.

QUINTANA-CABAÑAS, J. M. Pedagogía social. Madrid: Dykinson, 2001.

RUIZ, C. (Coord.). Educación social viejos usos y nuevos retos. València: Publ. Universitat de València, 2003.

SAMAGAIO, F. A educação social e a investigação: algumas generalidades em torno de um perfil profissional. Cadernos de Estudo, Porto, n. 3, p. 17-23, 2006.

SERAPICOS, A. M.; SAMAGAIO, F.; TREVISAN, G. Constructing and (re)constructing professional identities: na analysis on Portuguese social Educators. European Journal of Social Education, n. 20/21, p. 25-34, 2011.

SILVA, G. H. Educador Social: uma identidade a caminho da profissionalização. Educação e Pesquisa, São Paulo, v. 35, n. 3, p. 479-493, 2009. DOI: http://dx.doi.org/10.1590/S151797022009000300005

SILVA, R.; SOUZA, J. C.; MOURA, R.; MONTEIRO, E.; PESSAGNO, S. M. (Org.). Pedagogia social: contribuições para uma teoria geral da educação social. São Paulo: Expressão \& Arte Editora, 2011.

THOMPSON, N. Understandind social work. New York: Palgrave MacMillan, 2009.

RIAEE - Revista Ibero-Americana de Estudos em Educação, Araraquara, v. 15, n. esp. 3, p. 2167-2187, nov., 2020. e-ISSN: 1982-5587 
TIMÓTEO, I. A evolução da educação social: perspetivas e desafios contemporâneos. Praxis Educare - Revista da Associação dos Profissionais Técnicos Superiores de Educação Social, v. 1, p. 12-17, 2013.

TRILLA, J. El universo de la educación social. In: ROMANS, M.; PETRUS, A.; TRILLA, J. De profesión: educador(a) social. Barcelona: Paidós, 2000. p. 15-59.

TRILLA, J.; GROS, B.; LÓPEZ; F.; MARTÍN, M. J. La educación fuera de la escuela. Ámbitos no formales y educación social. Barcelona: Ed. Ariel, 2003.

TROTTER, C. Working with involutary clientes, a guide to practice. New York: Routledge, 2015.

ÚCAR, X. Exploring different perspectives of Social Pedagogy: towards a complex and integrated approach. Education Policy Analysis Archives, v. 21, n. 36, p. 1-17, 2013.

VARGAS, L. P. (Coord.). Nuevos espacios de la educación social. Bilbao: Publ. Universidad de Deusto, 1998.

VIEIRA, A. Educação social e mediação sociopedagógica. Porto: Profedições, 2013.

\section{Como referenciar este artigo}

MARTINS, E. C. A educação social nos novos espaços e tempos: as realidades entroncadas da intervenção social e educativa. Revista Ibero-Americana de Estudos em Educação, Araraquara, v. 15, n. esp. 3, p. 2167-2187, nov., 2020. e-ISSN: 1982-5587. DOI: https://doi.org/10.21723/riaee.v15iesp3.14423

Submetido em: 20/07/2020

Revisões requeridas em: 30/08/2020

Aprovado em: 29/09/2020

Publicado em: 30/10/2020 